\title{
Application of Al thinking visualization tool in the foreign language reading teaching
}

\author{
Ting Liu ${ }^{12}$, Takaya Yuizono ${ }^{2}$, Zhisheng Wang ${ }^{23}$, and Haiwen Gao ${ }^{3}$ \\ ${ }^{1}$ School of Foreign Languages, Dalian Polytechnic University, Dalian, Liaoning, China \\ ${ }^{2}$ School of Knowledge Science, Japan Advanced Institute of Science and Technology, Nomi, Ishikawa, Japan \\ ${ }^{3}$ Research Institute of Photonics, Dalian Polytechnic University, Dalian, Liaoning, China
}

\begin{abstract}
AI thinking visualization tool can express the knowledge in the brain in a graphical way. It can form an external manifestation of knowledge directly affecting the human senses, which is of great help for learners to improve their understanding, memory and thinking skills. In this research, we studied the mind mapping training through AI thinking visualization tool in the reading teaching of foreign language courses. The results indicated that via the independent establishment of a foreign language reading material framework based on AI thinking visualization tool, students' thinking skills and reading ability have been enhanced, learning enthusiasm has been improved, and good teaching results have been achieved.
\end{abstract}

\section{Introduction}

For the past few years, under the impetus of informationbased teaching, the application of thinking visualization tool in teaching has been developing constantly. As a technology that uses graphics and images as the main means, thinking visualization tool can show the thinking methods and thinking paths in the learning process through graphic technology. Human acquisition of external information is derived $80 \%$ or more from vision [1]. Thinking visualization tool can not only visually describe explicit knowledge, but also can make tacit knowledge explicit, so as to better achieve the development, dissemination and innovation of knowledge. The application of thinking visualization tool in the teaching process can promote students' critical thinking skills, and in the meantime can enhance students' performance and cooperative learning [2, 3]. Students who use thinking visualization tool to learn will better understand knowledge [4]. The tools currently adopted in thinking visualization mainly include mind map, concept map, cognitive map, semantic network, and so on. Among them, mind maps are the most widely researched and applied. In the actual development and application of thinking visualization, the most basic requirement is to be able to draw the mind map. Mind map is a representative thinking visualization tool, which is a method for concretizing abstract and divergent thinking, helping students master and understand knowledge, and develop creative thinking ability and logical ability. The continuous updating of technology has facilitated the development of thinking visualization tool. The application of some new thinking visualization computer software in teaching is gradually gaining attention, and is developing in a more targeted and more specific direction. Various AI thinking visualization tools have emerged one after another, and the representative mind mapping tools are Xmind, MindManager, Brainstorm, etc. In this study, AI thinking visualization tool Xmind was implemented into foreign language reading teaching, and the students can do the mind mapping training. The results indicated that mind mapping tool Xmind provided a new learning method for constructing a foreign language knowledge system, which stimulated students' interest in learning, and effectively developed their thinking ability and foreign language reading ability. And it has achieved good teaching application effect.

\section{Literature review}

As a graphical tool for characterization and materialization, mind map has both practicality and operability [5]. Assisted by lines, symbols, text, color and graphics elements, mind map is an effective tool of thinking. It shows learners' abstract thinking process which results in an intuitive and visual way, offering a view of the "forest" as well as the "trees", which can visualize the information and develop thinking ability greatly [6]. Mind mapping is a strategy that can visually display a large number of conceptual, hierarchical information in a concise and organized format [7]. In accordance with schema theory, reading comprehension is the process of materializing a schema by filling it with new information, which is directly understood or inferred [8]. The human mind has its own cognitive schema, which affects not only the interpretation of reading materials, but also the construction of new knowledge schemas [9]. Reading itself is not merely a language activity, as well as a thinking activity. In the process of reading, the reader

*Corresponding author's e-mail: hare677@126.com 
keeps constructing the context of the knowledge structure about the subject of the article [10]. In consequence, the theory of mind maps as a tool for knowledge visualization is consistent with schema-based reading teaching model. The use of mind map assists to fracture the difficult text passage into sentences and words to make them easier to understand. Mind map utilizes all the skills commonly associated with thinking, especially imagination, linking ideas, and flexibility. On account of these assumptions, learning using mind map is expected to map the students' minds and provoke their thinking in all directions and bring brilliant and creative ideas [11]. As an effective tool of thinking, mind map can develop students' potential and thinking ability considerably. One can visualize the results of abstract thinking and memorize information by applying this effective means of thinking [12]. The training of tactical skills in reading ability helps improve learners' reading levels, test scores, and memory of knowledge $[13,14]$. This paper proposed a pedagogy for reading teaching integrated with mind mapping training based on AI thinking visualization tool of Xmind. It is hoped that the results will provide empirical evidence to clarify the effectiveness of AI thinking visualization tool to enhance students' reading ability.

\section{Methods}

\subsection{Participants}

The participants consisted of 40 university students in two classes in the Japanese department of a language institute in Dalian city. The experimental group (20 students) and control group (20 students) had roughly the same Japanese-language expertise skills, and the numbers and gender balance of participants were almost equal.

\subsection{Design and procedure}

Both group received an 8-week practical lecture. The experimental group's reading teaching was integrated with mind mapping training based on AI thinking visualization tool of Xmind, and the control group was taught a regular curriculum. The mind mapping training in reading teaching mainly followed the following principles:1) Comprehensive understanding of reading materials before drawing mind maps;2) Integrate scattered information of reading materials to understand the main idea;3) Use association actively to promote memory and understanding, and stimulate creative thinking. The features of the drawn mind map are:1) Use the central image to express the main content; 2) Branches are mainly composed of subject sentences and keywords. Figure 1 is a mind map based on Xmind. It can clearly show the structure of articles, so that students can more clearly understand and grasp the specific details of each paragraph, and analyze the structure and content of the article in detail. After class, they can continue to diverge their thinking on this topic and add more content to this mind map. It's expected to visualize the reading materials and improve understanding it.

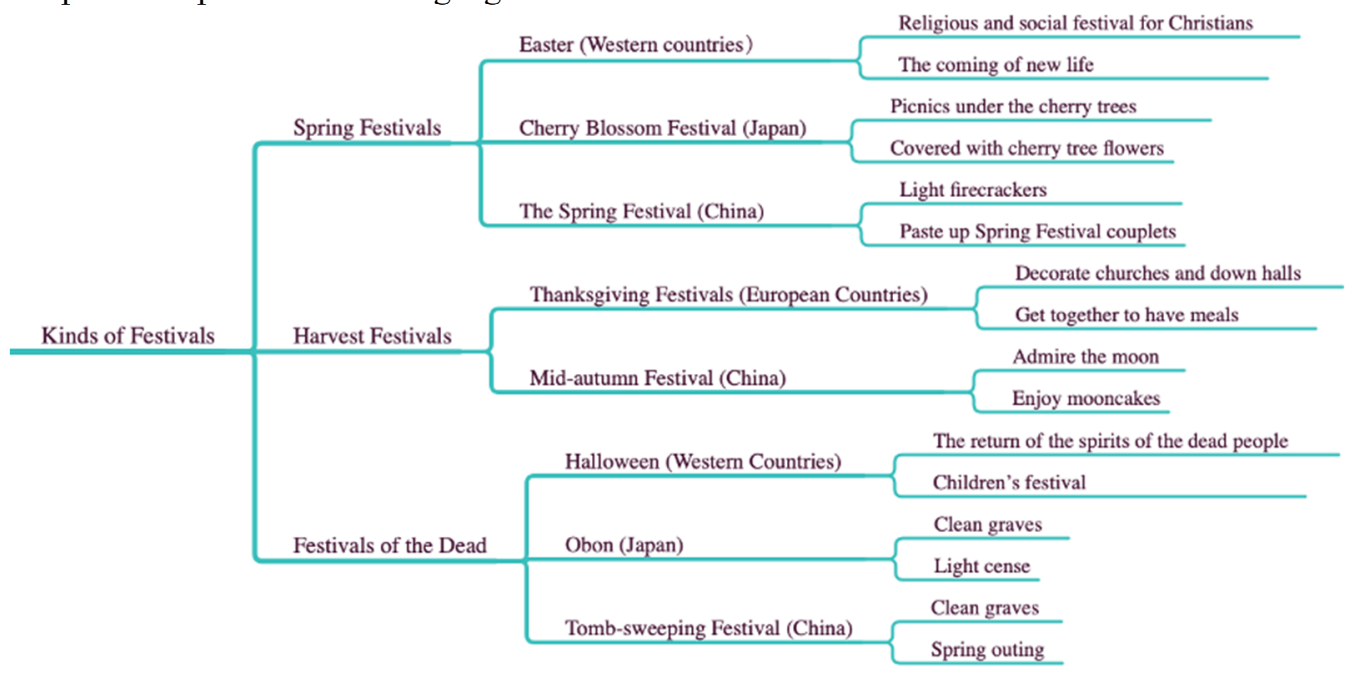

Figure 1. Mind mapping based on Xmind

\subsection{Instruments}

In order to investigate the effect of mind mapping training based on AI thinking visualization tool, this paper compared and analyzed the reading comprehension scores of the two groups through a pre-test and post-test repeated-measures design. In addition, a motivation questionnaire was performed to investigate the experimental group' learning motivation.

\subsubsection{Reading comprehension test}

In the reading comprehension test, the students will read five Japanese articles and complete the test within a given time limit: 50 minutes. Each article was followed by four reading comprehension multiple-choice questions, and the students should write down the keywords and main sentences in each article. 


\subsubsection{Motivation questionnaire}

A learning motivation questionnaire was conducted to clarify whether this pedagogy is an attraction to motivate and interest the experimental students. Motivation in language learning is modelled as a three-step process involving choice motivation (requires fostering a fun, supportive atmosphere in the lecture), executive motivation (requires instructors to make learning exciting and enjoyable), and increased motivation (requires increasing the learner's satisfaction) [15]. Based on this research, the motivation questionnaire in this study consisted of three subscales, each with 2 items: choice motivation (ex: This pedagogy were interesting; Study in a free atmosphere), executive motivation (ex: Deepen understanding; Acquisition of new knowledge), and enhance motivation (ex: Sense of accomplishment; Recommending this to juniors). All answered are evaluated in 5 grades evaluation (1 agree, 2 slightly agree, 3 neither agree nor disagree, 4 slightly disagree, 5 disagree). There is also a free description section in the questionnaire in order to allow students to elaborate on their ideas about the exercises [16].

\section{Results and discussion}

\subsection{Reading comprehension scores}

T-test was conducted on comparison of scores in reading comprehension pre-test and post-test (Table 1). It confirmed that the experimental group received higher mean scores in the post-test than the control group did, and the increase between the post-test and pre-test was significant $(t=-16.66, p=.000(\mathrm{p}<0.001))$.

Table 1. The t-test results of reading comprehension scores for the two groups.

\begin{tabular}{|c|c|c|c|c|c|c|c|c|c|}
\hline \multirow{2}{*}{ Item } & \multirow{2}{*}{ Group } & \multicolumn{3}{|c|}{ Pre-test } & \multicolumn{3}{|c|}{ Post-test } & \multirow{2}{*}{$t$} & \multirow{2}{*}{$p$} \\
\hline & & $\mathrm{N}$ & M & SD & $\mathrm{N}$ & $\mathrm{M}$ & SD & & \\
\hline $\begin{array}{c}\text { Reading } \\
\text { comprehension }\end{array}$ & $\begin{array}{l}\text { EG } \\
\text { CG }\end{array}$ & $\begin{array}{l}20 \\
20\end{array}$ & $\begin{array}{l}73.85 \\
73.95\end{array}$ & $\begin{array}{l}2.30 \\
1.88\end{array}$ & $\begin{array}{l}20 \\
20\end{array}$ & $\begin{array}{l}81.35 \\
74.75\end{array}$ & $\begin{array}{l}2.00 \\
2.12\end{array}$ & $\begin{array}{c}-16.66 \\
-1.18\end{array}$ & $\begin{array}{l}.000 \\
.253\end{array}$ \\
\hline
\end{tabular}

(Note. $\mathrm{EG}=$ Experimental Group; $\mathrm{CG}=$ Control Group)

The significant increase in the experimental students' score in reading comprehension post-test suggests that the use of AI thinking visualization tool can help enhance reading ability. The elaborative thinking process improved students' access to their own knowledge as compared to what could be achieved via rote learning or repetition. The AI thinking visualization tool facilitated students' use of Japanese language creatively. Through mind mapping based on AI thinking visualization tool, the classroom atmosphere was activated, and students' confidence and interest in reading was enhanced, which was conducive to stimulating students' learning motivation and improving students' reading skills.

\subsection{Motivation questionnaire}

As to the effect of mind mapping based on AI thinking visualization tool on learning motivation, we used a learning motivation questionnaire. The results are shown in Table 2. It shows that most of students got a good evaluation in all question items. In addition, the feedback from the free description section was generally positive: "I like the current reading teaching methods very much"; "Mind mapping based on Xmind is very interesting, which can improve my concentration and associativity in the reading process"; "Mind mapping enhanced my learning motivation"; "I am satisfied with the current reading teaching"; "Besides reading teaching, I think this AI thinking visualization tool can also be applied in other foreign language classes, such as writing training ". Students enjoyed themselves in the experimental Japanese class and reported positive emotions about the reading teaching they received. This might reflect that AI thinking visualization tool can effectively improve students' learning motivation. It can foster a fun atmosphere, make learning exciting and enjoyable, increase students' satisfaction. Therefore, it can simultaneously enhance students' learning motivation and reading ability

Table 2. Results of learning motivation questionnaire.

\begin{tabular}{cccccc}
\hline Item & Agree & $\begin{array}{c}\text { Slightly } \\
\text { agree }\end{array}$ & $\begin{array}{c}\text { Neither agree } \\
\text { nor disagree }\end{array}$ & $\begin{array}{c}\text { Slightly } \\
\text { disagree }\end{array}$ & Disagree \\
\hline Interesting & $87.22 \%$ & $11.08 \%$ & $1.25 \%$ & $0.43 \%$ & $0.02 \%$ \\
Study in a free atmosphere & $89.76 \%$ & $8.33 \%$ & $1.32 \%$ & $0.58 \%$ & $0.01 \%$ \\
Deepen understanding & $83.12 \%$ & $9.53 \%$ & $4.36 \%$ & $2.95 \%$ & $0.04 \%$ \\
Acquisition of new knowledge & $84.52 \%$ & $8.41 \%$ & $3.78 \%$ & $3.24 \%$ & $0.05 \%$ \\
Sense of accomplishment & $84.33 \%$ & $11.17 \%$ & $2.89 \%$ & $1.54 \%$ & $0.07 \%$ \\
Recommending this to juniors & $85.23 \%$ & $10.35 \%$ & $1.87 \%$ & $2.43 \%$ & $0.12 \%$ \\
\hline
\end{tabular}




\section{Conclusions}

In foreign language courses, the cultivation and development of students' thinking ability is an important content of teaching. The application of thinking visualization tool in classroom teaching serves an important way to effectively promote the development of students' thinking ability. In this study, the AI thinking visualization tool Xmind was applied to visualize the reading materials in the reading teaching, which makes the classroom knowledge vivid and easy for students to understand and master. In addition, it improves students' thinking ability and reading ability, and stimulates students' learning motivation and enthusiasm. In the future research, during mind mapping process in the AI thinking visualization tool, resources such as pictures, videos, sounds, texts, web pages, etc. can be linked. It can help explain and understand the information in the mind map, so that students can establish memory links of topic keywords with sounds, images, colors, etc. This can make the teaching of knowledge more vivid and active in the classroom atmosphere, and thus increase students' interest in learning. In addition, it will actively mobilize students' senses of hearing, sight, touch, etc., to more easily follow the teachers' lecture ideas, with more focus on learning and thinking.

\section{Acknowledgments}

This work was supported by China Scholarship Council (Grant number: 201908050172), Liaoning Province 2018 Research Project on Undergraduate Teaching Reform in General Higher Education (Grant number: Educational Department of Liaoning Province [2018] No. 471), Liaoning Science Research Program of the Education Department (Grant number: J2019025), Dalian Institute of Social Sciences Major Research Program (Grant number: 2019dlsky058), and 2019 Training Program of Teaching Achievement Award (Grant number: Teaching Affaires Office in DPU [2020] No.6).

\section{References}

1. Cai, J.Q., Chen, K., Hu, L.M., Du, P. (2013). A new method of assessing LED lighting impact on the visual comfort level. China Illum. Eng. J, 24, 22-26.

2. Rosciano, A. (2015). The effectiveness of mind mapping as an active learning strategy among associate degree nursing students[J]. Teaching \& Learning in Nursing, 10, 93-99.

3. Shatri, K., Buza K. (2017). The Use of Visualization in Teaching and Learning Process for Developing Critical Thinking of Students. European Journal of Social Sciences Education \& Research, 9, 71.

4. Buran, A., Filyukov A. (2015). Mind Mapping Technique in Language Learning. Procedia - Social and Behavioral Sciences, 206, 215-218.
5. Buzan,T., Buzan, B. (2010). The Mind Map Book, BBC Active, Harlow, UK.

6. Hyerle, D. (1996). Visual tools for constructing knowledge. Alexandria, VA: Association for Supervision and Curriculum Development.

7. Budd, J. W. (Winter 2004). Mind maps as classroom exercises. The Journal of Economic Education, 35, $35-46$.

8. Christin, Nuttall. (1982). Teaching Reading Skills in a Foreign Language. London: Heinemann Educational.

9. Krashen, S. D. (1982). Principles and practice in second language acquisition. Oxford: Pergamon.

10. Grabe,W. (2005). Teaching and researching reading. Foreign Language Teaching and Research.

11. Buzan, T., Buzan, B. (1993). The Mind Map Book: How to Use the Radiant Thinking to Maximize Your Brain's Untapped Potential. Penguin Book Ltd., London.

12. Chiou, C.-C. (2008). The effect of concept mapping on students' learning achievements and interests. Innovations in Education and Teaching International, 45, 375-387.

13. Andrew, D. C. (1998). Strategies in Learning and Using a Second Language. London: Longman.

14. Coleman, J., Klapper, J. (2005). Effective learning and teaching in modern languages. London: Routledge.

15. DÖrnyei, Z. (2001). Motivational Strategies in the Language Classroom. Cambridge University.

16. Liu, T.,Yuizono, T., Lu,Y. F., Wang, Z. S. (2019). Application of Human-Machine Dialogue in Foreign Language Teaching at Universitie, IOP Conference Series: Materials Science and Engineering, doi:10.1088/1757-899X/573/1/012047. 